\title{
PEMBERDAYAAN MASYARAKAT KELURAHAN GEBANG PUTIH-SURABAYA DALAM MENGELOLA SAMPAH RUAMAH TANGGA MENGGUNAKAN KOMPOSTER SEDERHANA
}

\author{
Dyah Suci Perwitasari'1), Nur Aini Fauziyah²), Kusuma Wardhani Mas'udah') \\ 1)Departemen Teknik Kimia, Fakultas Teknik, Universitas Pembangunan Nasional "Veteran" Jawa Timur, Gunung \\ Anyar, Surabaya 60294, Indonesia. \\ ${ }^{2)}$ Departemen Teknik Mesin, Fakultas Teknik, Universitas Pembangunan Nasional "Veteran” Jawa Timur, Gunung \\ Anyar, Surabaya 60294, Indonesia. \\ Corresponding author: Nur Aini Fauziyah \\ E-mail: aini.zierra@gmail.com
}

\begin{abstract}
ABSTRAK
Penyuluhan tentang pembuatan kompos organik rumah tangga telah dilakukan di Kelurahan Gebang Putih, Surabaya. Minimnya lahan dan lokasi perumahan yang padat menjadi tantangan terbesar dalam pengomposan. Oleh karena itu, pembuatan kompos sederhana dari sampah organik rumah tangga turut dikembangkan pada penyuluhan ini. Metode yang dikembangkan pada pengabdian ini adalah dengan penyuluhan langsung bersama warga setempat. Tahapan penyuluhan adalah pemilahan sampah, pembuatan kompos organik sederhana, dan diakhiri dengan praktek dalam membuat kompos organik sederhana. Sedangkan dalam pembuatan kompos dalam skala rumah tangga sangatlah mudah. Ember bekas sebagai media komposter cukup dilubangi bagian bawahnya. Sampah coklat (daun kering, tanah, dst) ditumpuk dengan sampah hijau (sayuran, kulit buat, dst) yang disusun dengan bergantian hingga memenuhi ember. Kemudian, air leri ditambahkan di atas tumpukan sampah tersebut sebagai cairan bioaktivator. Setelah diberikan penyuluhan dan pelatihan, warga mengakui bahwa wawasan dalam mengolah sampah di tengah keterbatasan lahan menjadi lebih terbuka, mudah dan tidak berbau. Keberhasilan pelatihan ini juga didukung oleh kuisioner akhir yang mana rata-rata kemampuan peserta tentang pembuatan kompos meningkat sebesar $83 \%$ dari sebelumnya.
\end{abstract}

Kata Kunci: komposter; sampah organik; air leri.

\begin{abstract}
The training on making household organic compost has been accomplished in Gebang Putih, Surabaya. The lack of land and dense housing locations were the biggest challenges in composting. Therefore, making simple compost from household organic waste was also developed in this counseling. The method developed in this service was direct counseling with local residents. The counseling stages were waste sorting, making simple organic compost, and ending with practice in making simple organic compost. Meanwhile, making compost on a household scale was easy. The used bucket as a composter media was enough to make a hole at the bottom. Brown waste (dried leaves, soil, etc.) was stacked with green waste (vegetables, leather, etc.) which were arranged alternately until they fill the bucket. Then, leri water was added on top of the pile of waste as a bioactivator liquid. After being given counseling and training, the residents acknowledged that the insight in processing waste in the midst of limited land became more open, easy and odorless. The success of this training was also supported by the final questionnaire where the average ability of participants in composting increased by $83 \%$ from the previous one.
\end{abstract}

Keywords: composter; organic trash; lei water.

\section{PENDAHULUAN}

Surabaya sebagai kota dengan jumlah penduduk yang cukup padat di Indonesia. Keadaan ini pasti disertai dengan tingginya jumlah sampah yang dihasilkan penduduk tiap harinya. Sementara itu, pusat pengelolaan sampah dengan sistem $3 R$ (reduce, reuse, recycle) belum berjalan di semua kelurahan di kota Surabaya (Lidwina, 2021). Sebagian kecil dari sampah $(7 \%)$ yang telah berhasil didaur ulang dan sebagian besar (69\%) berakhir di TPA.

Pengolahan sampah sangatlah penting bagi kehidupan kita secara berkesinambungan. Manfaat pengolahan sampah adalah mengurangi timbunan sampah, membuka lapangan kerja, mengurangi bahaya penyakit, dan turut serta dalam mengembangkan kreatifitas masyarakat (Dirgantara, 2013; Lestari, 2015; Ratu dkk., 2020). 
Berdasarkan data BPS pada tahun 2019, Kelurahan Gebang Putih merupakan salah satu kelurahan yang berada di pusat kota Surabaya dengan jumlah penduduk \pm 7.771 jiwa (Badan Pusat Statistik, 2019). Kepadatan penduduk ini diperparah dengan lokasi kelurahan gebang putih yang dekat dengan pusat kota (dekat dengan kampus, pusat perbelanjaan, pasar tradisional, TPA, apartemen, dst). Sehingga, sebagian besar rumah memiliki kamar yang disewakan untuk para pekerja maupun mahasiswa. Oleh karena itu, akumulasi sampah akan semakin banyak dan akan membahayakan lingkungan apabila tidak diolah dengan baik.

Berdasarkan hasil survei yang kami lakukan, sektor rumah tangga dan rumah makan menjadi sumber terbesar penyumbang sampah di wilayah Surabaya. Setiap rumah tangga minimal menghasilkan 0,75-2 $\mathrm{kg}$ sampah organik tiap harinya. Selain itu, warga kelurahan Gebang Putih mayoritas membuang sampah tanpa mengolah atau memilahnya terlebih dahulu. Kondisi masyarakat yang didominasi oleh ibu rumah tangga kurang mengetahui tentang teknologi komposter dan potensi ekonomi dari pengolahan sampah yang dilakukan.

Berdasarkan kodisi di atas, kurangnya pengetahuan dan ketrampilan masyarakat dalam mengelola sampah organik rumah tangga secara sederhana akan menimbulkan permasalahan besar bagi lingkungan. Jika permasalahan sampah ini dapat mulai diselesaikan dari skala rumah tangga, maka masalah sampah akan sedikit terkurangi dan dampak besarnya akan dirasakan dalam jangka panjang.

Salah satu pengolahan sampah organik rumah tangga yang dapat dilakukan adalah dengan komposter (Perwitasari dan Siswati, 2020). Pengolahan sampah organik rumah tangga dapat dilakukan secara ringkas dan sederhana. Seperti yang telah dikembangkan sebelumnya, komposter dengan teknik takakura (Astuti dkk., 2018). Teknik pengomposan dengan takakura memanfaatkan keranjang pori (keranjang loundry) sebagai media pengomposan. Teknik ini sangat cocok diterapkan pada wilayah perkotaan yangminim lahan. Akan tetapi, apabila tidak dilapisi kardus di sisi samping keranjang, maka bau tidak sedap akan turut mencemari lingkungan. Selain itu, komposter lain menggunakan cacing sebagai organisme pengurai juga telah dikembangkan oleh Biruntha (Biruntha dkk., 2020). Tetapi, teknik ini kurang cocok apabila diterapkan di wilayah perkotaan karena akan kesulitan dalam mencari cacing sebagai organisme pengurainya.
Oleh karena itu, berdasarkan analisis pada uraian di atas, beberapa hal yang dianggap sebagai permasalahan prioritas yang harus ditangani, yaitu 1) pengetahuan tentang pemilahan sampah, 2) pengetahuan tentang pengomposan khususnya pada sampah organik rumah tangga, 3) praktek dalam membuat kompos sederhana. Semua produk yang digunakan dalam komposter sederhana ini berasal dari limbah rumah tangga, baik sampah organiknya maupun cairan bioaktivatornya (yaitu dari air cucian beras atau air leri) (Respati dan Cahyadi, 2018). Kedepannya, pengatahuan komposter sederhana pada sampah organik rumah tangga diharapkan dapat menjadi alternatif dalam pengolahan sampah organik rumah tangga secara mandiri dan berkelanjutan dengan memanfaatkan barang bekas yang ada (ember maupun air leri).

\section{METODE}

Pelaksanaan kegiatan pengabdian ini dilaksanakan selama 3 bulan, antara bulan Juni sampai bulan Agustus bertempat di RW. 03 Kelurahan Gebang Putih, Kecamatan Sukolilo, Surabaya. Metode yang dilakukan pada pengabdian masyarakat ini adalah sebagai berikut:

a. Ceramah dan tanya jawab dengan kader penggerak PKK dan warga di RW.03 Kelurahan Gebang Putih, Kecamatan Sukolilo, Surabaya, terkait proses pengolahan sampah yang selama ini dilakukan dan informasi tentang komposter sederhana. Pemaparan tentang teknik pemilahan sampah dan teknik pengomposan juga turut disampaikan narasumber dalam pengabdian masyarakat ini.

b. Demonstrasi/praktik langsung untuk membuat kompos organik sederhana dari sampah rumah tangga.

Adapun langkah sederhana dalam pebuatan kompos organik menggunakan komposter sederhana (Gambar 1) adalah sebagai berikut:

1. Menyiapkan komposter sederhana dari ember bekas dengan melubangi sisi bawah ember

2. Mengisi komposter dengan susunan seperti pada Gambar 1 yaitu sampah coklat (tanah, daun kering, dst) dan diikuti sampah hijau (sayuran, kulit buah, cangkang telur, dst) disusun secara berlapis. 
3. Menyiram kompos dengan air cucian beras sebagai bahan bioaktivator (pengganti EM4).

4. Perbandingan susunan sampah coklat atau tanah dengan sampah organik adalah 2:1 (artinya dua lapisan sampah coklat untuk satu lapis sampah hijau).
5. Tutup komposter agar selalu hangat dan letakkan komposter di luar ruangan. Biarkan selama \pm 1 minggu, aduk dan cek secara berkala kelembabannya. Apabila terlalu basah, kita dapat menambahkan sampah coklat. Apabila terlalu kering, kita bisa menambahkan air cucian beras.
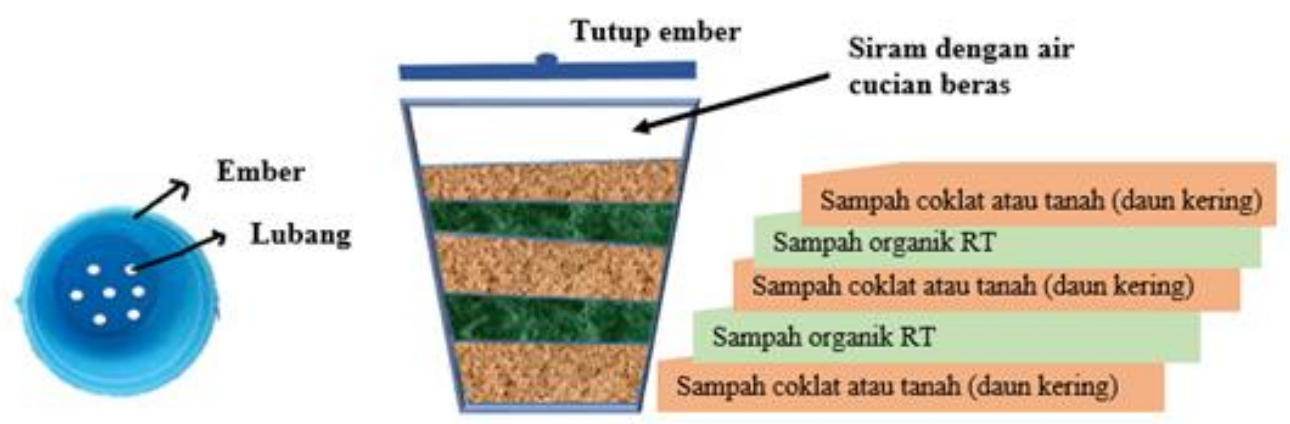

Gambar 1. Desain komposter sederhana untuk sampah organik rumah tangga (RT).

c. Praktik mandiri. Warga akan mempraktikkan langsung secara mandiri di rumah masing-masing untuk membuat kompos organik sederhana dari sampah yang dihasilkan tiap harinya. Sampahsampah sayuran sisa memasak dapat digunakan sebagai bahan kompos.

d. Evaluasi keberhasilan

Dalam mengevaluasi keberhasilan pelatihan ini, kami turut membagikan kuisioner sebelum dan sesudah kegiatan. Peserta diminta menjawab beberapa pertanyaan yang ada pada kuisioner (pre dan post kuisioner).

Indikator keberhasilan dari kegiatan pelatihan ini adalah warga mampu membuat kompos sendiri secara mandiri dan berkelanjutan. Selain itu, pengetahuan akan teknik dan mabfaat pengomposan juga sangat penting untuk dimiliki warga. Sehingga, setelah kegiatan pelatihan ini, warga akan semakin produktif dan mandiri dalam segi pangan, lingkungan, maupun ekonomi kedepannya.

\section{HASIL DAN PEMBAHASAN}

Kegiatan pelatihan dan pemberdayaan masyarakat RW. 03 Kelurahan Gebang Putih, Kecamatan Sukolilo, Surabaya, telah dilakukan sesuai jadwal yang telah ditentukan sesuai dengan kesepakatan dengan mitra pengabdian. Gambar 2 menunjukkan kegiatan pelatihan di Balai RW.03 Kelurahan Gebang Putih. Mengingat pelatihan dilaksanakan pada saat pandemi COVID-19, protokol kesehatan pun diterapkan dengan sangat ketat. Semua peserta dan narasumber menggunakan masker, disinfektan, dan dicek suhu tubuhnya sebelum memasuki ruangan (Gambar 3).

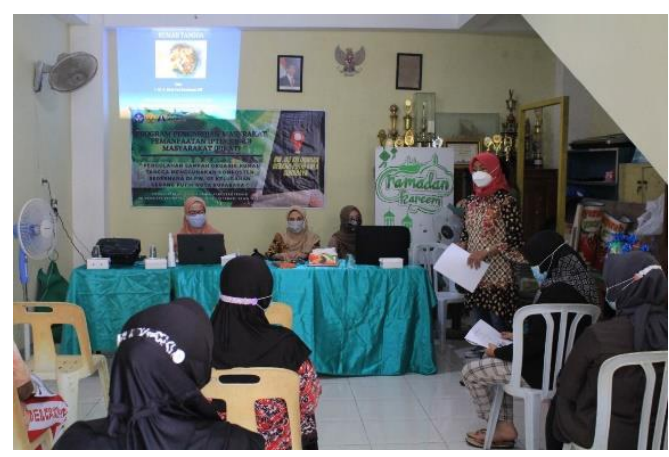

Gambar 2. Pelattihan pembuatan kompos organik sederhana di Balai RW. 03 Kelurahan Gebang Putih, Kecamatan Sukolilo, Surabaya.

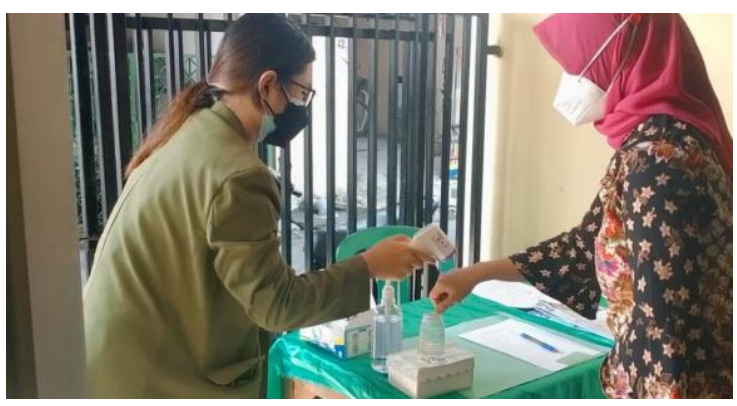

Gambar 3. Penerapan protokol kesehatan saat pelatihan.

Pelatihan pembuatan kompos organik sederhana diawali dengan pemaparan terkait pemilahan sampah. Materi ini berisi pengetahuan akan jenis-jenis sampah. Berdasarkan data kuisioner awal, sebanyak $80 \%$ peserta langsung membuang sampah di 
tampat sampah tanpa memilahnya terlebih dahulu. Pemilaha sampah ini sangat penting dilakukan karena menjadi tahap awal dalam pengolahan sampah selanjutnya. Seperti yang telah diteliti sebelumnya, sampah organik dan anorganik memiliki sifat yang berbeda sehingga pengolahan yang dilakukan pun harus berbeda (Setyawati, 2013). Sampah organik akan mudah terurai oleh mikroorganisme, sedangkan sampah anorganik memerlukan waktu ratusan tahun untuk dapat diuraikan (Marzuki dkk., 2018). Sehingga sampah anorganik biasanya diolah dengan mendaur ulang atau memanfaatkannya menjadi kerajinan yang bernilai ekonomis. Oleh karena itu, pemilahan sampah dari skala rumah tangga seharusnya dilakukan sejak dini.

Selajutnya, pemaparan tentang beberapa teknik pengomposan pada limbak organik rumah tangga, diantaranya dengan teknik takakura (Astuti dkk., 2018), penambahan cacing sebagai organisme pengurai (Biruntha dkk., 2020), biopori, compostbag, serta kontainer sebagai media komposter. Dengan mempertimbangkan keunggulan, kelemahan beberapa teknik pengomposan tersebut dan menyesuaikannya terhadap kondisi di wilayah Gebang Putih, teknik pengomposan sederhana dengan ember (seperti yang terlihat pada Gambar 1) dipilih untuk dikembangkan. Berdasarkan informasi dari kuisioner dan tanya jawab saat pelatihan, warga beranggapan bahwa pengomposan terutama pada sampah organik memerlukan peralatan yang kompleks, lahan yang luas, serta menghasilkan bau yang kurang sedap. Beberapa hal tersebutlah yang membuat warga tidak mecoba untuk membuat kompos.

Demonstrasi pembuatan kompos turut dilakukan pada pelatihan ini. Salah satu narasumber bersama perwakulan peserta mempraktekkan pembuatan kompos organik sederhana (Gambar 4). Susunan sampah coklat dan sampah hijau sesuai dengan desain pada Gambar 1. Setelah sampah memenuhi ember, air leri (air cucian beras) sapat disiramkan di atas sampah $( \pm 100 \mathrm{ml})$ untuk setiap perbandingan 2 sampah coklat dan 1 sampah hijau. Penyiraman air leri dan pengadukan pada kompos dilakukan setiap 3 hari sekali. Sampah hijau mulai membusuk pada hari ke-6. Air leri (pengganti EM4) berfungsi sebagai pemercepat pengomposan. Mikroorganisme yang terdapat pada air leri mampu mempercepat proses penguraian bahan organik melalui fermentasi aerob. Sehingga pengadukan kompos secara berkala akan meningkatkan sirkulasi oksigen sehingga pengomposan berlangsung lebih singkat dan tidak berbau (Wahyono dkk., 2012). Guna melindungi kompos dari hewan melata, kompos harus ditutup rapat.

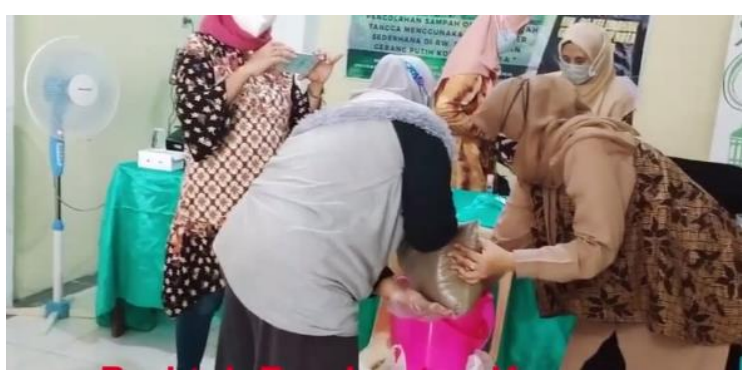

Gambar 4. Demonstrasi pembuatan kompos organik sederhana

Keberhasilan pelatihan pengomposan diukur dari tanya jawab antara narasumber dan peserta. Selain itu, keberhasilan ini juga didukung oleh kuisioner akhir yang mana ratarata kemampuan peserta tentang pembuatan kompos meningkat sebesar $83 \%$ dari sebelumnya. Sebelumnya peserta pelatihan hanya terfokus pada peralatan kompos yang rumit dan untuk mendapatkannya peserta harus membeli. Tetapi setelah adanya pelatihan ini, peserta merasa bahwa pemanfaatan limbah ember bekas dan air leri sebagai media komposter dianggap lebih sederhana, ekonomis, ramah lingkungan, dan mudah. Ember cukup dilubangi sisi bawahnya dan siap digunakan untuk membuat kompos organik. Dengan demikian, ketrampilan dan pengtahuan tentang pengomposan organik peserta semakin meningkat.

Berdasarkan informasi dari kuisioner akhir, permasalahan lanjutan muncul dari kegiatan pelatihan ini. Apabila kompos telah terkumpul banyak, kopos akan dimanfaatkan dan dipasarkan kemana. Oleh karena itu, kegiatan ini diharapkan akan dapat belangsung secara berkelanjutan sehingga kompos organik rumah tangga ini bisa menjadi peluang usaha bagi masyarakat setempat.

\section{SIMPULAN DAN SARAN Simpulan}

Pelatihan pembuatan kompos organik sederhana berhasil meningkatkan pemahaman dan menjadi alternatif pengiolahan sampah organik skala rumah tangga bagi warga RW.03, Kelurahan Gebang Putih, Kecamatan Sukolilo, Surabaya. Pengolahan sampah diawali dengan pemilahan sampah pada skala rumah tangga, dan dilanjutkan dengan pengomposan sederhana. Pemanfaatan ember bekas dan air leri menjadi media yang mudah, ramah lingkungan, dan ekonomis.

\section{Saran}

Pelatihan seharusnya dilakukan secara jangaka panjang dan adanya pendampingan 
khusus. Selain itu, pengetahuan akan potensi pemasaran kompos perlu dikenalkan kepada warga agar membuka peluang usaha kedepannya.

\section{DAFTAR RUJUKAN}

Astuti, Y., Tafiprios, T., dan Widayati, C. C., 2018, TAKAKURA COMPOST MAKING TRAINING JOGLO VILLAGE, WEST JAKARTA, ICCD, Vol. 1, no. 1, pp 692-699

Badan Pusat Statistik, 2019, https://surabayakota.bps.go.id/staticta ble/2020/06/22/755/banyaknyapenduduk-menurut-kewarganegaraandan-jenis-kelamin-kecamatan-sukolilotahun-2019.html, diakses tanggal 15 Mei 2021.

Biruntha, M., Karmegam, N., Archana, J., Karunai Selvi, B., John Paul, J. A., Balamuralikrishnan, B., Chang, S. W., dan Ravindran, B., 2020, Vermiconversion of Biowastes with Low-to-High $\mathrm{C} / \mathrm{N}$ Ratio into Value Added Vermicompost, Bioresource Technology, Vol. 297, pp 122398

Dirgantara, I. M. B., 2013, Pengetahuan mendaur ulang sampah rumah tangga dan niat mendaur ulang sampah, Jurnal Studi Manajemen Organisasi, Vol. 10, no. 1, pp 1-12

Lestari, N. P., 2015, Studi Tentang Kepedulian Masyarakat dalam Pengelolaan Sampah di Kelurahan Sumur Batu Kecamatan Bantar Gebang Kota Bekasi, Advance Access published 2015

Lidwina, A., 2021, Banjir Sampah Plastik Selama Pandemi - Analisis Data Katadata.co.id, https://katadata.co.id/timredaksikatada ta/analisisdata/5fc719de77307/banjirsampah-plastik-selama-pandemi diakses tanggal 15 Mei 2021.

Marzuki, R. D., Sugito, R., dan Atmaja, T. H. W., 2018, SAMPAH ANORGANIK SEBAGAI ANCAMAN DI KAWASAN EKOSISTEM HUTAN MANGGROVE KUALA LANGSA, Jurnal Jeumpa, Vol. 5, no. 2, pp 84-90

Perwitasari, D. S. dan Siswati, N. D., 2020, PENGELOLAAN SAMPAH TERPADU DI KELURAHAN MEDOKAN AYU, Jurnal Abdimas Teknik Kimia, Vol. 1, no. 01, pp 17-21

Ratu, M. R., Keban, A., dan Sogen, J. G., 2020, PENGOLAHAN SAMPAH ORGANIK RUMAHTANGGA MENJADI PUPUK BOKASHI SERTA PEMANFAATANNYA BAGI TANAMAN REMPAH DAN PENINGKATAN PENDAPATAN DI KELURAHAN PENFUI, Jurnal Pengabdian Masyarakat Peternakan, Vol. 5, no. 1

Respati, R. dan Cahyadi, H., 2018, Cara Pembuatan Komposter Rumahan Sederhana, PengabdianMu: Jurnal IImiah Pengabdian kepada Masyarakat, Vol. 3, no. 2, pp 177-183

Setyawati, L. M., 2013, Potensi Sampah Organik Menjadi Pupuk Organik pada Kawasan Perkantoran, Jurnal Permukiman, Vol. 8, no. 1, pp 45-52

Wahyono, S., Widanarko, S., Moersidik, S. S., dan Djajadiningrat, S. T., 2012, METABOLISME PENGELOLAAN SAMPAH ORGANIK MELALUI TEKNOLOGI KOMPOSTING DI WILAYAH INTERNAL PERKOTAAN, Jurnal Teknologi Lingkungan, Vol. 13, no. 2, pp 179-192 